\title{
Application of Recycled Zero-Valent Iron Nanoparticle to the Treatment of Wastewater Containing Nitrobenzene
}

\author{
Heon Lee, ${ }^{1}$ Byung-Hoon Kim, ${ }^{2}$ Young-Kwon Park, ${ }^{3}$ Sun-Jae Kim, ${ }^{4}$ and Sang-Chul Jung ${ }^{1}$ \\ ${ }^{1}$ Department of Environmental Engineering, Sunchon National University, 255 Jungang-ro, Sunchon, \\ Jeonnam 540-950, Republic of Korea \\ ${ }^{2}$ Department of Dental Materials, School of Dentistry, Chosun University, Gwangju 501-759, Republic of Korea \\ ${ }^{3}$ School of Environmental Engineering, University of Seoul, 163 Seoulsiripdae-ro, Dongdaemun-gu, Seoul 130-743, Republic of Korea \\ ${ }^{4}$ Faculty of Nanotechnology and Advanced Materials Engineering, Sejong University, Seoul 143-747, Republic of Korea
}

Correspondence should be addressed to Sang-Chul Jung; jsc@sunchon.ac.kr

Received 22 September 2015; Accepted 16 November 2015

Academic Editor: Yuan-Cheng Cao

Copyright (C) 2015 Heon Lee et al. This is an open access article distributed under the Creative Commons Attribution License, which permits unrestricted use, distribution, and reproduction in any medium, provided the original work is properly cited.

Zero-valent iron (ZVI) was synthesized using iron oxide, a byproduct of pickling line at a steel work. ZVI with a mean particle size of $500 \mathrm{~nm}$ was synthesized. The reaction activity of the synthesized ZVI was much higher than commercial ZVI. When applied to the decomposition of nitrobenzene (NB), the ZVI particles underwent corrosion and passivation oxide film formation, resulting in particle size decrease. The NB decomposition rate increased with increasing ZVI dosage level and with decreasing $\mathrm{pH}$. The solution $\mathrm{pH}$ increased monotonously with increasing reaction duration, whereas the aniline concentration showed a maximum at $50 \mathrm{~min}$. Based on the GC/MS analysis, NB is presumed to be reduced into aniline via reductive intermediates such as azobenzene and azoxybenzene. When combined with a subsequent biological process, the synthesized ZVI will be able to decompose NB in wastewater effectively.

\section{Introduction}

Nitrobenzene (NB) is an important feedstock material used widely for the production of various chemical products such as aniline, pharmaceuticals, dyes, and pesticides [1]. When disposed inadequately, however, NB can be a dangerous pollutant contaminating surface water and groundwater and hence endangering aquatic organisms and humans [2]. NB can be a significant threat to environment even at low concentrations [3]. Conventional biological treatment is often not effective in removing NB contained in water because of the electron-deficient character of nitro-groups that make NB resistant to the decomposition by microorganisms $[4,5]$. A number of different advanced oxidation processes have been examined for the treatment of NB-containing wastewater: ozonation and $\mathrm{O}_{3} / \mathrm{UV}$ processes [6], photocatalysis [7], photoassisted Fenton oxidation [8], supercritical oxidation [9], and other processes [10]. However, these processes are either expensive or ineffective.
Zero-valent iron (ZVI) is a mild reducing agent with a reduction potential of $-0.440 \mathrm{~V}$. It has been widely used as a reactive medium to reduce nitro compounds contained in groundwater because the reduced products (amido compounds) are much less toxic and can be biodegraded easily [11-13]. However, ZVI has an important drawback: high production cost. The production of ZVI from waste iron oxide generated in steel works is one way to reduce the production cost.

In the steel industry, the oxide scale layer formed on the surface of carbon steel is removed using acid pickling process, during which waste acid is generated as a byproduct. Acid stock solution is recovered from this waste acid using roasting process, during which iron oxide $\left(\mathrm{Fe}_{2} \mathrm{O}_{3}\right)$ is generated as a byproduct. Depending on the content of impurities, the iron oxide generated from the roasting process is divided into high-grade and low-grade iron oxides. High-grade iron oxide is used as ferrite, whereas low-grade iron oxide is used as pigment. Recent rapid growth of Chinese steel market has 
caused oversupply of low-grade iron oxide. Landfilling of iron oxide can cause the contamination of soil and groundwater. Therefore, finding new applications of low-grade iron oxide is in urgent need. Low-grade iron oxide was used in this study. Under the assumption that the price of low-grade iron oxide, which is mostly disposed as waste, is zero, the total cost of the synthesis of S-ZVI using transfer type reactor was calculated to be about $7 \mathrm{us} \$ / \mathrm{kg}$. Hot-air dryers are installed in the pickling lines of steel works for drying iron oxide. Therefore, using these hot-air dryers can decrease the operation cost of transfer type reactor. In addition, the use of reducing gases, which are produced in the steel works as byproducts, can decrease further the cost of the synthesis of S-ZVI, making it virtually zero. Therefore, the S-ZVI production process is highly economical mass manufacturing process.

We have reported the generation of ZVI from lowgrade iron oxide using fixed-bed and transfer type reductor [14-16]. In this study, ZVI was applied to the degradation of NB contained in water. The activity of ZVI generated from low-grade iron oxide was compared with that of commercial ZVI. The effects of $\mathrm{pH}$ and ZVI dose on the NB degradation efficiency were investigated. The morphology, size, and composition of ZVI particles were observed using a transmission electron microscope (TEM) before and after the degradation experiments. The reductive products were analyzed using GC/MS measurements to suggest the mechanism for the degradation of $\mathrm{NB}$ in the presence of ZVI.

\section{Materials and Methods}

2.1. Zero-Valent Iron. ZVI was synthesized by reducing iron oxide obtained from the pickling line of a steel work located in Gwangyang city, South Korea. This ZVI will be referred to as S-ZVI hereafter. A transfer type reductor and $\mathrm{H}_{2}$ gas were used to reduce iron oxide. The physicochemical characteristics of iron oxide were reported in a previous study [14]. The characteristics and detailed synthesis procedure of S-ZVI were also reported previously [16]. Commercial iron powder (C-ZVI hereafter) with $98 \%$ purity and the particle diameter of 120 150 $\mu \mathrm{m}$ was purchased from Kanto Chemical Co. for the purpose of comparison.

2.2. Degradation Experiments. Nitrobenzene $\left(\mathrm{C}_{6} \mathrm{H}_{5} \mathrm{NO}_{2}\right)$ purchased from Junsei Chemical Co. Ltd. was used as the target pollutant. The $\mathrm{pH}$ of reaction solution was adjusted using hydrochloric acid (Daejung Chemicals \& Metals Co., Ltd.). Only reagent-grade chemicals and pure water (Daejung Chemicals \& Metals Co., Ltd.) were used in this study. $1 \mathrm{mM}$ $\mathrm{NB}$ solution was prepared by adding $0.12306 \mathrm{~g}$ of $\mathrm{NB}$ to $1 \mathrm{~L}$ of pure water and then stirring the mixture for $24 \mathrm{~h} .100 \mathrm{~mL}$ of this solution and a certain amount $(0.025 \sim 0.10 \mathrm{~g})$ of ZVI were mixed in a $250 \mathrm{~mL}$ Erlenmeyer flask placed in a shaker to allow the NB degradation reaction to occur. Samples were taken after defined reaction durations from the reaction solution to measure the concentration and determine the reaction rate.
2.3. Analytical Methods. The NB concentration of the reaction solution was measured using high performance liquid chromatography (HPLC, model 1200, Agilent Co.) equipped with a C-18 column (ZORBAX Eclipse XDB, Agilent Co. Ltd., $150 \mathrm{~mm} \times 4.6 \mathrm{~mm}$, particle size $5 \mu \mathrm{m}$ ). Samples were injected using an injection valve equipped with a $20 \mu \mathrm{L}$ loop. Methanol and water mixture $(70: 30 \mathrm{v} / \mathrm{v})$ was used as mobile phase, with a flow rate of $0.5 \mathrm{~mL} / \mathrm{min}$. The UV detector wavelength was set to $280 \mathrm{~nm}$. The changes in morphology, size, and composition of S-ZVI particles were observed using high resolution field emission transmission electron microscope (HR-FETEM, JEM-2100F, JEOL). Gas chromatography mass spectrometer/headspace autosampler (GC/MS, QP2000, Shimadzu Co. Ltd.) equipped with HP 5 MS column $(30 \mathrm{~m} \times 0.25 \mathrm{~mm} \times 0.25 \mu \mathrm{m})$ was used to analyze the reaction intermediates and to investigate the mechanism for the decomposition of NB by ZVI. After being maintained at $60^{\circ} \mathrm{C}$ for $2 \mathrm{~min}, \mathrm{GC} / \mathrm{MS}$ temperature was increased to $300^{\circ} \mathrm{C}$ at a rate of $30^{\circ} \mathrm{C} / \mathrm{min}$ and then was maintained at the final temperature for $6 \mathrm{~min}$.

\section{Results and Discussion}

3.1. Characterization of S-ZVI. Figure 1 shows HR-FETEM images of iron oxide and S-ZVIs. The size of iron oxide particles before the reduction to $\mathrm{S}-\mathrm{ZVI}$ by $\mathrm{H}_{2}$ gas was approximately $200 \mathrm{~nm}$ (Figure 1(a)). This small particle size stems from the abrasion between floating particles during the synthesis in the fluidized bed roaster. The S-ZVI generated from iron oxide using a transfer type reactor was shown to have a much larger size than the iron oxide particles (Figure 1(b)). This was attributed to the sintering among the particles occurring during the reduction reaction at a high temperature $(873 \mathrm{~K})$. A previous study reported that the mean particle size of generated using a transfer type reactor increased with increasing reduction temperature [15]. The decomposition of NB using ZVI is usually conducted at low $\mathrm{pH}$ conditions to enhance the decomposition rate. In this study, the solution $\mathrm{pH}$ was lowered by adding $\mathrm{HCl}$. The corrosion at a low $\mathrm{pH}$ was expected to change the morphology and size of ZVI particles. Therefore, the SZVI particles used for the NB decomposition at a $\mathrm{pH}$ of 2 were observed using HR-FETEM (Figures 1(c) and 1(d)). After the reaction for $30 \mathrm{~min}$, the size of the S-ZVI particles slightly decreased (Figure 1(c)) compared to that before the reaction (Figure 1(b)) and the particle shape became sharper. When the reaction lasted for $60 \mathrm{~min}$, much more significant decrease in particle size was observed (Figure $1(\mathrm{~d})$ ). This result indicates that $\mathrm{S}-\mathrm{ZVI}$ particles were corroded into $\mathrm{Fe}^{2+}$ by the reaction with $\mathrm{H}^{+}$ions, inducing the reduction of $\mathrm{NB}$, accompanied by the change in particle shape and size. ZVI is dissolved as $\mathrm{Fe}^{2+}$ ions as the reaction proceeds and remaining iron mud can be removed using centrifugation and filtration.

The S-ZVI particles synthesized in this study are easily oxidized upon the exposure to air because of their nanoscale size. Therefore, iron particles reduced in the transfer type reactor were first cooled in an oxygen-free hopper and then placed in a nitrogen-filled glass bottle, which was stored in a 


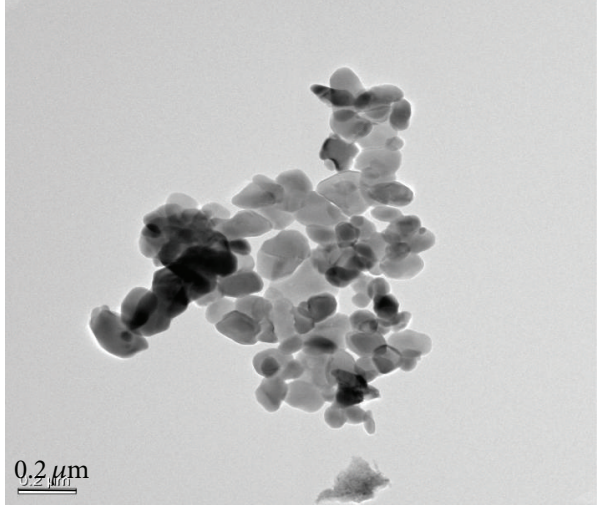

(a)

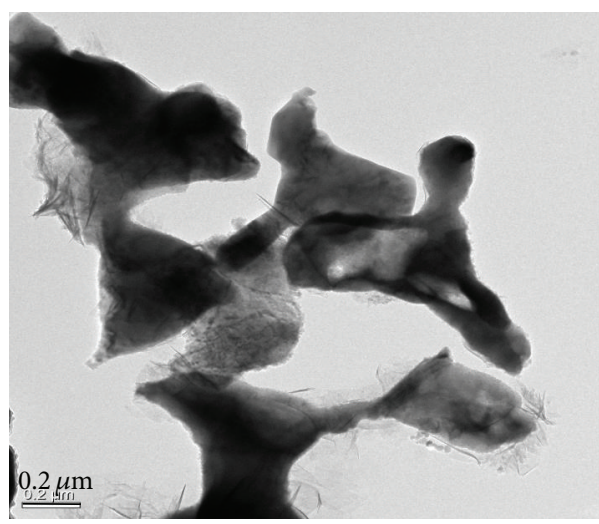

(c)

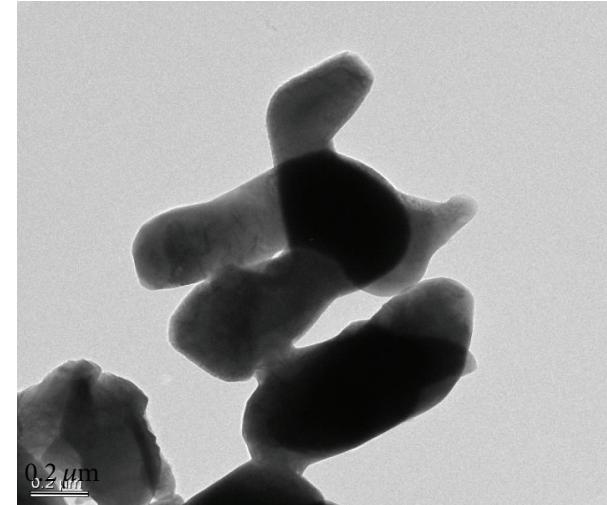

(b)

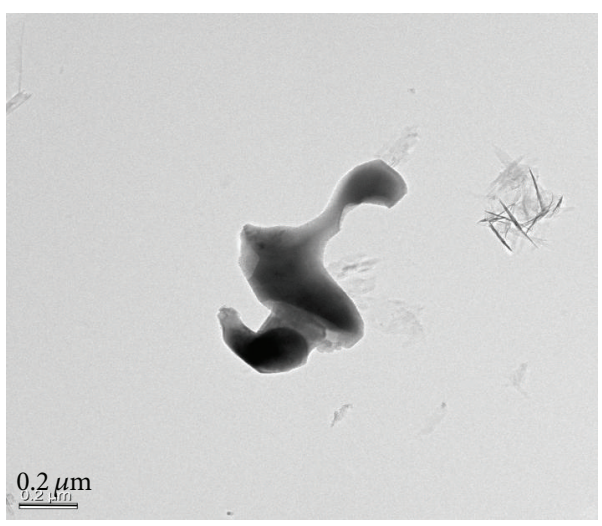

(d)

Figure 1: HR-FETEM images of iron oxide and S-ZVIs. (a) Iron oxide, (b) as-prepared S-ZVI, (c) S-ZVI after the reaction for 30 min, and (d) S-ZVI after the reaction for $60 \mathrm{~min}$.

low-temperature desiccator. Nevertheless, a passivation oxide film is formed on the surface of S-ZVI because of trace oxygen existing around the particles. However, this passivation oxide film has a positive effect of preventing rapid oxidation of SZVI. Figure 2 compares the HR-FETEM images and energy dispersive spectroscopy (EDS) line scanning profiles of S-ZVI particles before the reaction (a) and after the reaction for $30 \mathrm{~min}$ at $\mathrm{pH}$ of 2 (b). The iron and oxygen content profiles shown in the right-hand side were obtained along the lines indicated in the left-hand-side images. The oxygen content shown in Figure 2(b) was much smaller than that shown in Figure 2(a), implying the corrosion of passivation oxide film during the NB decomposition reaction. Generally, the passivation oxide film of iron is composed of $\mathrm{FeO}, \mathrm{Fe}_{2} \mathrm{O}_{3}$, and $\mathrm{Fe}_{3} \mathrm{O}_{4}$, which are readily corroded in acids. Reaction (1) is believed to be able to explain the corrosion of the passivation oxide film by $\mathrm{HCl}$, added for $\mathrm{pH}$ adjustment:

$$
\begin{array}{r}
\mathrm{Fe}_{x} \mathrm{O}_{y}(\mathrm{~s})+z \mathrm{HCl}(\text { aq. }) \longrightarrow \mathrm{Fe}_{x} \mathrm{Cl}_{z} \text { (aq.) }+y \mathrm{H}_{2} \mathrm{O} \text { (aq.) } \\
(z=2 y)
\end{array}
$$

3.2. Effect of $p H$. The important role of $\mathrm{pH}$ in the NB decomposition using ZVI has been reported by several previous studies [17-19]. The effects of $\mathrm{pH}$ on the decomposition of
NB using S-ZVI were examined in this study. Figure 3 shows the change in $\mathrm{pH}$ of reaction solution during the degradation of NB with the S-ZVI dosage of $1.0 \mathrm{~g} / \mathrm{L}$ and the initial $\mathrm{pH}$ of 1.5. The solution $\mathrm{pH}$ increased monotonously with reaction time. Previous studies [12, 20] suggested that the corrosion ZVI producing hydroxide ions is the reason of $\mathrm{pH}$ increase during the decomposition of NB. $\mathrm{O}_{2}$ is the preferred oxidant under oxic conditions, leading to rapid corrosion as shown in Reaction (2). Further oxidation of $\mathrm{Fe}^{2+}$ may result in the formation of $\mathrm{Fe}^{3+}$ :

$$
\mathrm{Fe}^{0}+\frac{1}{2} \mathrm{O}_{2}+\mathrm{H}_{2} \mathrm{O} \longrightarrow \mathrm{Fe}^{2+}+2 \mathrm{OH}^{-}
$$

Under anoxic conditions, on the other hand, water serves as the preferred oxidant as shown in Reaction (3):

$$
\mathrm{Fe}^{0}+2 \mathrm{H}_{2} \mathrm{O} \longrightarrow \mathrm{Fe}^{2+}+\mathrm{H}_{2}+2 \mathrm{OH}^{-}
$$

3.3. Degradation Kinetics of NB by ZVIs. The activity of S-ZVI synthesized in this study was compared with that of C-ZVI. Figure 4 shows the NB concentration decays obtained with the two ZVIs. The dosage of ZVI was $1.0 \mathrm{~g} / \mathrm{L}$ and the solution $\mathrm{pH}$ was 2.0. The NB removal using C-ZVI was represented well by the pseudo first-order kinetic model with a reaction rate constant of $0.05032 \mathrm{~min}^{-1}$. On the other hand, the NB 

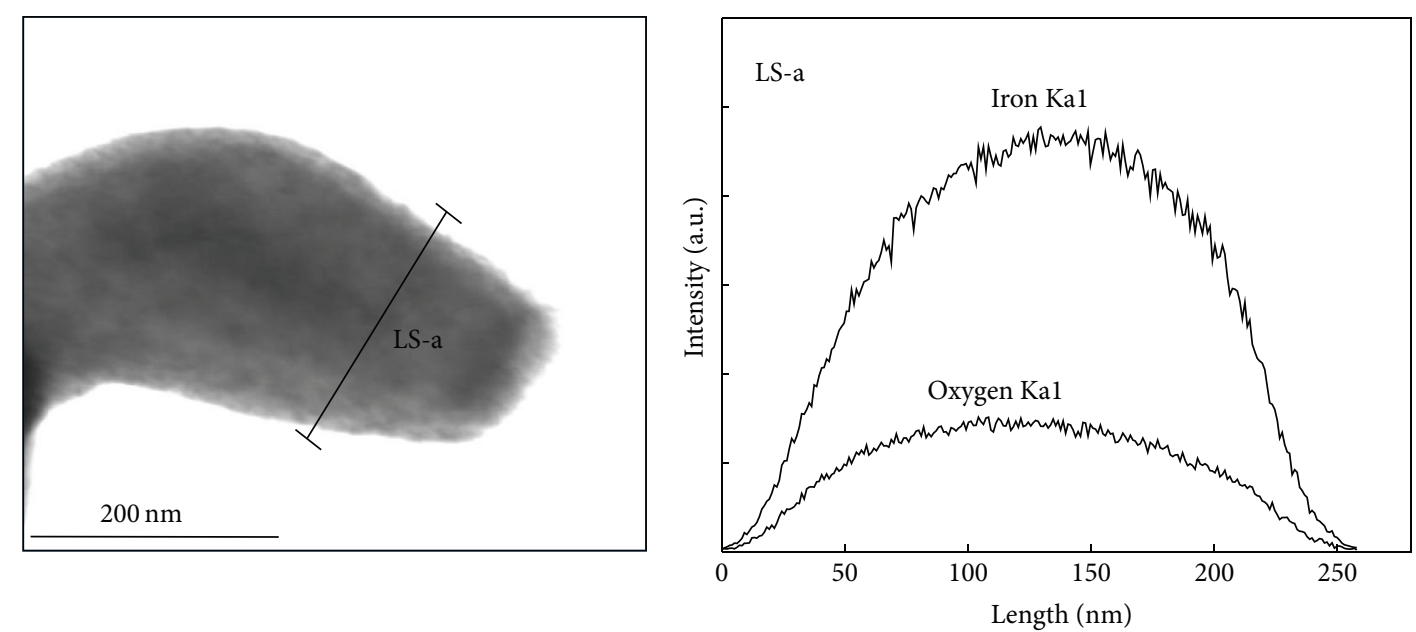

(a)
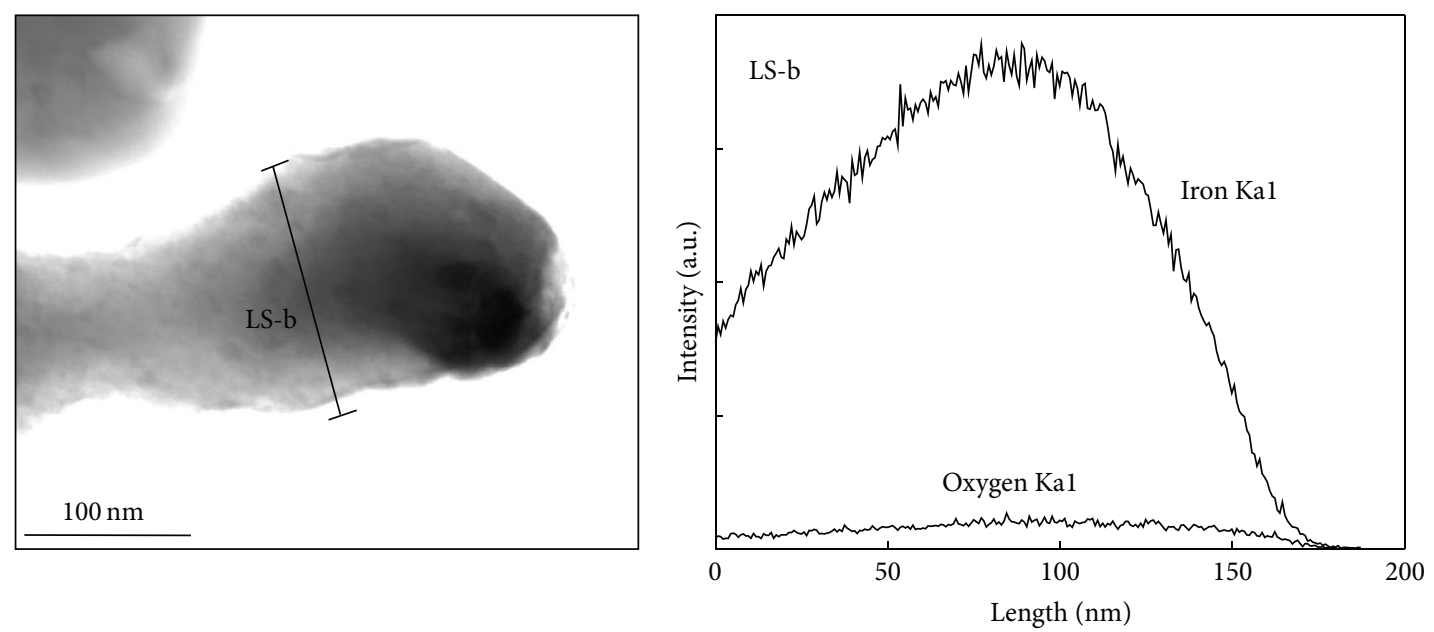

(b)

FIGURE 2: HR-FETEM images and EDS line scanning profiles of S-ZVI. (a) As-prepared S-ZVI and (b) S-ZVI after the reaction for 30 min.

removal using S-ZVI could not be explained by a first-order reaction. When the reaction rate constants were calculated based on the first-order kinetics, the reaction rate constant obtained with S-ZVI was 2.65 times larger than that obtained with C-ZVI. This result was attributed to the large difference in the particle diameters of C-ZVI $(120 \sim 150 \mu \mathrm{m})$ and S-ZVI $(\sim 500 \mathrm{~nm})$ and hence the large difference in the particle surface area. Reportedly, the dechlorination of halocarbon is influenced strongly by the surface area of ZVI particles $[21,22]$. This is in good agreement with the result of this study showing a significant effect of ZVI particle surface area on the NB decomposition rate. This result implies that the reactive sites on the ZVI particles are involved in the decomposition of NB.

In the presence of ZVI, the reduction of nitro group is the dominant process for the transformation of NB. The reduction of NB by ZVI produces aniline during which nitrosobenzene and phenylhydroxylamine are formed as reaction intermediates as shown in Reactions (4)-(7) [12]:

$$
\mathrm{Fe}^{0} \longrightarrow \mathrm{Fe}^{2+}+2 \mathrm{e}^{-}
$$

$$
\begin{gathered}
\left(\mathrm{C}_{6} \mathrm{H}_{5}\right) \mathrm{NO}_{2}+2 \mathrm{H}^{+}+2 \mathrm{e}^{-} \longrightarrow\left(\mathrm{C}_{6} \mathrm{H}_{5}\right) \mathrm{NO}+\mathrm{H}_{2} \mathrm{O} \\
\left(\mathrm{C}_{6} \mathrm{H}_{5}\right) \mathrm{NO}+2 \mathrm{H}^{+}+2 \mathrm{e}^{-} \longrightarrow\left(\mathrm{C}_{6} \mathrm{H}_{5}\right) \mathrm{NHOH} \\
\left(\mathrm{C}_{6} \mathrm{H}_{5}\right) \mathrm{NHOH}+2 \mathrm{H}^{+}+2 \mathrm{e}^{-} \longrightarrow\left(\mathrm{C}_{6} \mathrm{H}_{5}\right) \mathrm{NH}_{2}+\mathrm{H}_{2} \mathrm{O}
\end{gathered}
$$

The overall reaction can then be written as

$$
\begin{aligned}
& \mathrm{C}_{6} \mathrm{H}_{5} \mathrm{NO}_{2}+3 \mathrm{Fe}^{0}+6 \mathrm{H}^{+} \\
& \quad \longrightarrow \mathrm{C}_{6} \mathrm{H}_{5} \mathrm{NH}_{2}+3 \mathrm{Fe}^{2+}+2 \mathrm{H}_{2} \mathrm{O}
\end{aligned}
$$

The participation of $\mathrm{H}^{+}$in the overall reaction indicates the role of $\mathrm{pH}$ determining the decomposition rate of $\mathrm{NB}$. Figure 5 compares the decays of $\mathrm{NB}$ concentration obtained with different solution $\mathrm{pH}$ values (1.5 5). The dosage of $\mathrm{S}$ ZVI was $1.0 \mathrm{~g} / \mathrm{L}$. The NB decomposition rate increased with decreasing $\mathrm{pH}$. In particular, the effect of $\mathrm{pH}$ was dramatic when $\mathrm{pH}$ was lower than 2.5. More than $99.9 \%$ of NB was decomposed within $30 \mathrm{~min}$ at $\mathrm{pH}$ of 1.5. Rejuvenation of ZVI by aqueous $\mathrm{Fe}^{2+}$ was also reported by previous studies $[18,23] . \mathrm{Fe}^{2+}$ released under weak acidic conditions played 


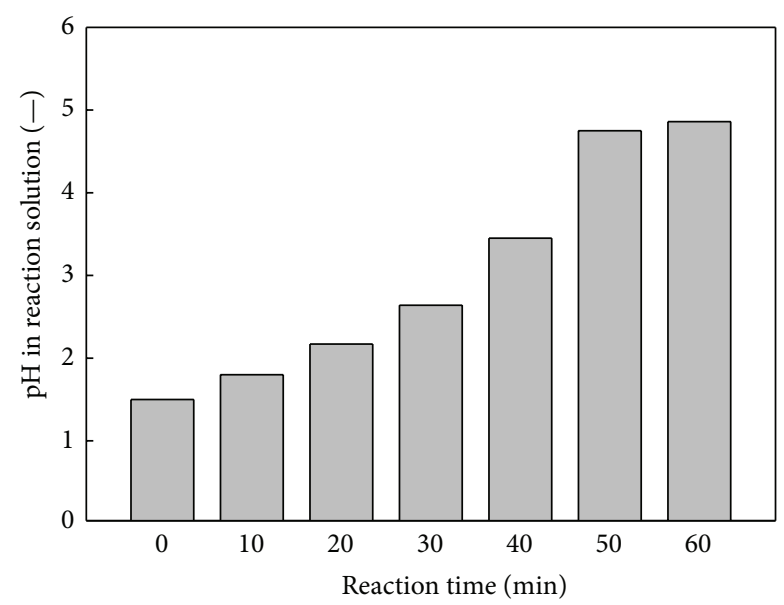

FIgure 3: The change in $\mathrm{pH}$ of reaction solution during the degradation of NB by S-ZVI. The dosage of S-ZVI was $1.0 \mathrm{~g} / \mathrm{L}$ and initial $\mathrm{pH}$ of solution was 1.5 .

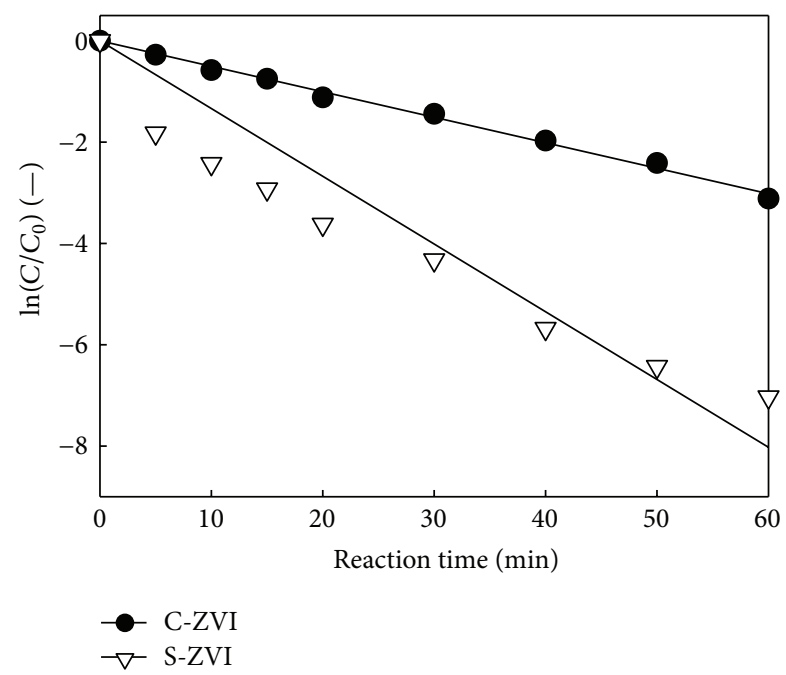

FIGURE 4: Comparison of the activities of C-ZVI and S-ZVI for the degradation of NB. The dosage of ZVI was $1.0 \mathrm{~g} / \mathrm{L}$ and $\mathrm{pH}$ of solution was 2.0.

a significant role in promoting the reaction [18]. High $\mathrm{pH}$ leads to the formation of iron hydroxide precipitates on the ZVI particle surface (passivation oxide film), limiting further dissolution and hence reducing the NB decomposition rate.

The effect of S-ZVI dosage on the NB decomposition rate was examined. Figure 6 compares the NB concentration decays obtained with different dosage levels of S-ZVI. The solution $\mathrm{pH}$ was 2.0. The NB removal rate increased with increasing S-ZVI dosage. The pseudo first-order kinetic theory explained well the NB decomposition obtained with small S-ZVI dosage levels, whereas the result obtained with the largest S-ZVI dosage level $(1.00 \mathrm{~g})$ could not be represented by the pseudo first-order kinetic theory.

3.4. Reductive Pathways of NB by S-ZVI. GC/MS analysis was performed to investigate the main products and mechanism

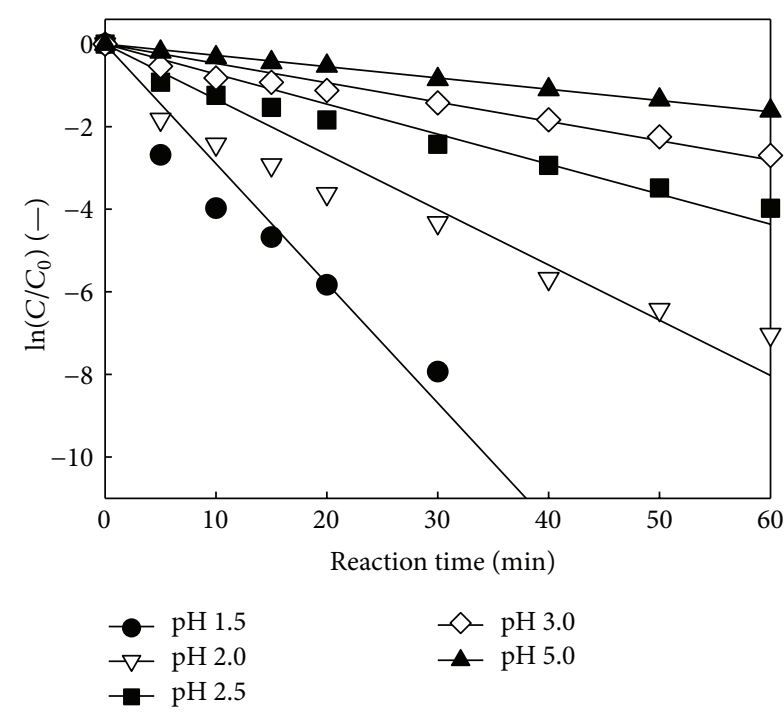

FIgURE 5: Decay of NB concentration obtained with different solution $\mathrm{pH}$ values. The dosage of S-ZVI was $1.0 \mathrm{~g} / \mathrm{L}$.

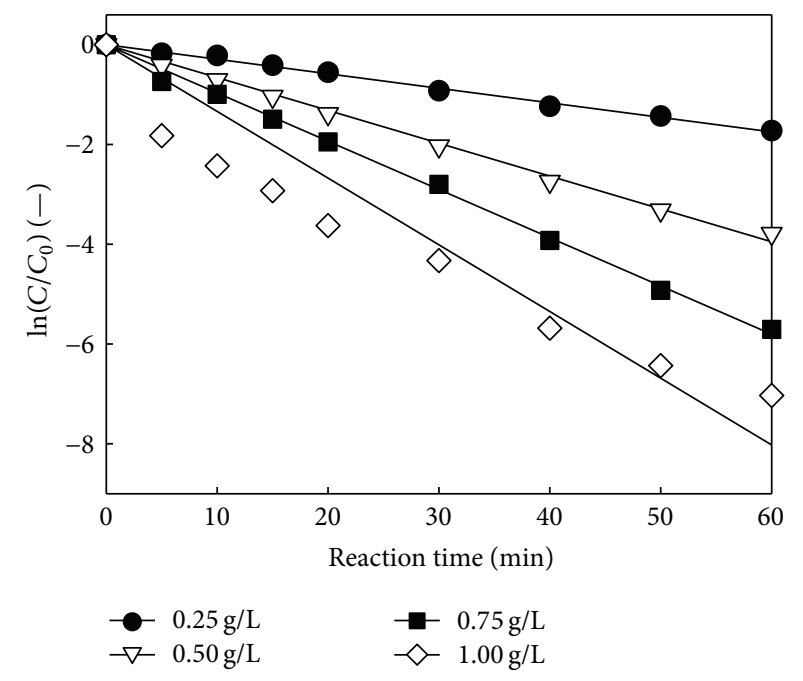

FIGURE 6: Decay of NB concentration obtained with different S-ZVI dosage levels. The solution $\mathrm{pH}$ was 2.0 .

of NB decomposition by S-ZVI. Figure 7 shows the GC/MS spectra of the reductive products of $\mathrm{NB}$ obtained with the initial NB concentration of $1 \mathrm{mM}$, the solution $\mathrm{pH}$ of 2.0 , the reaction time of $20 \mathrm{~min}$, and the S-ZVI dosage level of $1.00 \mathrm{~g} / \mathrm{L}$. Peaks were observed at the retention times of $3.93 \mathrm{~min}$ ((a), aniline), $4.80 \mathrm{~min}$ ((b), nitrobenzene), $7.45 \mathrm{~min}$ ((c), azobenzene), and $8.28 \mathrm{~min}((\mathrm{~d})$, azoxybenzene). The reduction of NB by ZVI is known to produce aniline via nitrosobenzene and phenyl hydroxylamine, forming azobenzene and azoxybenzene as reaction intermediates [5]. Figure 7 shows that the reaction for $20 \mathrm{~min}$ in the presence of S-ZVI removed NB (peak (b)) considerably, while forming reductive products such as azobenzene, azoxybenzene, and aniline. 


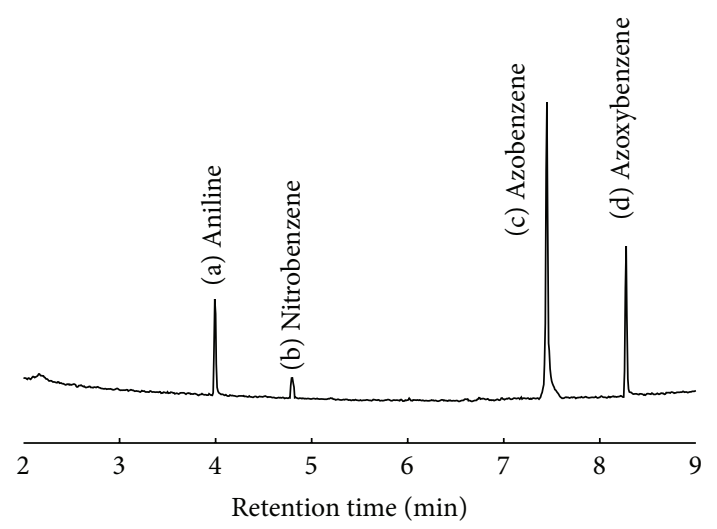

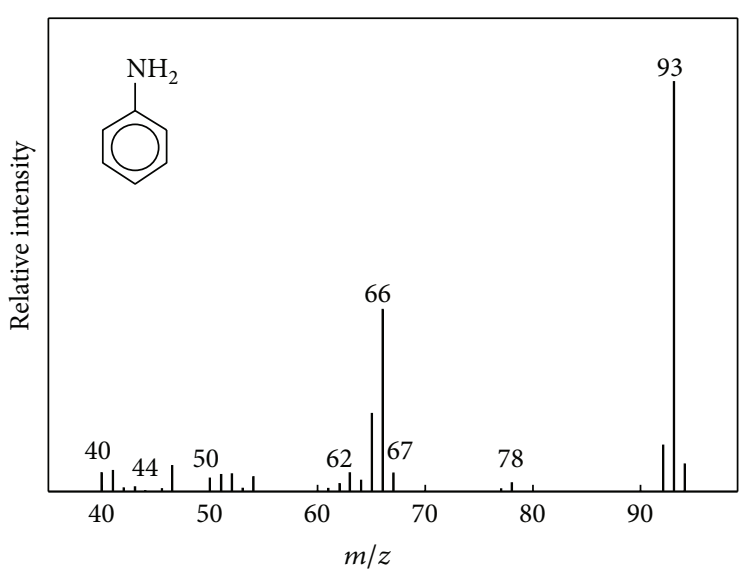

(a) Aniline

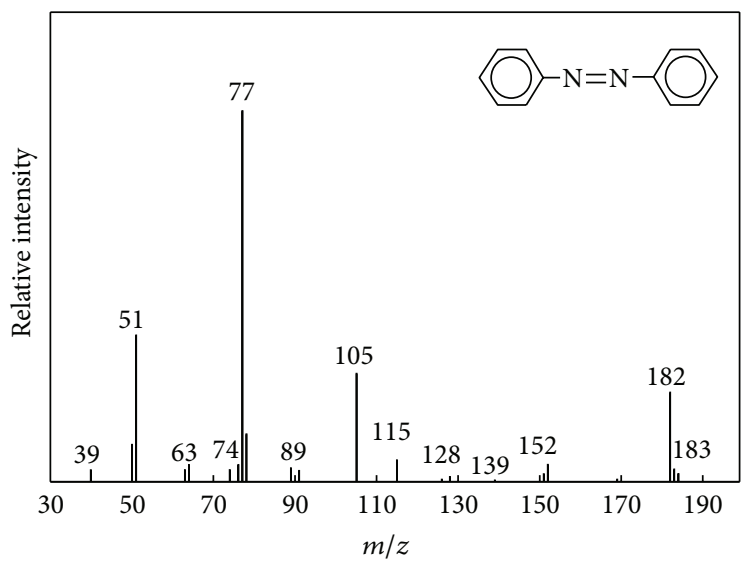

(c) Azobenzene

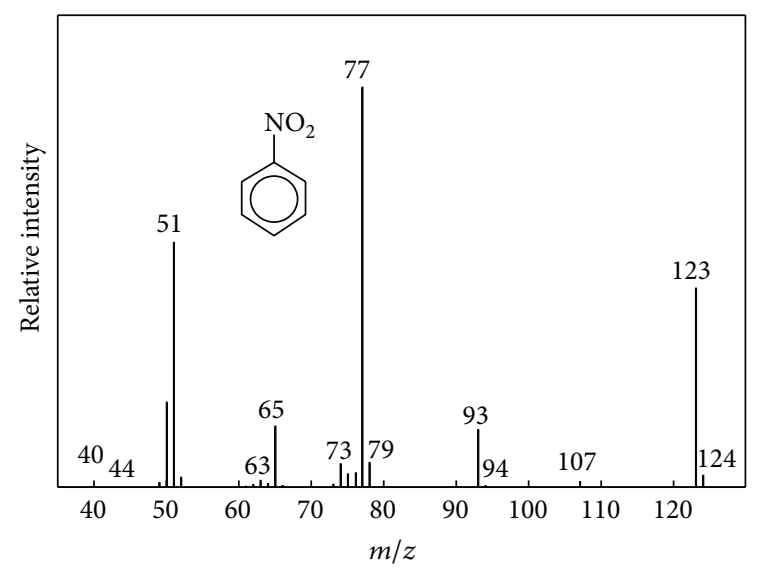

(b) Nitrobenzene

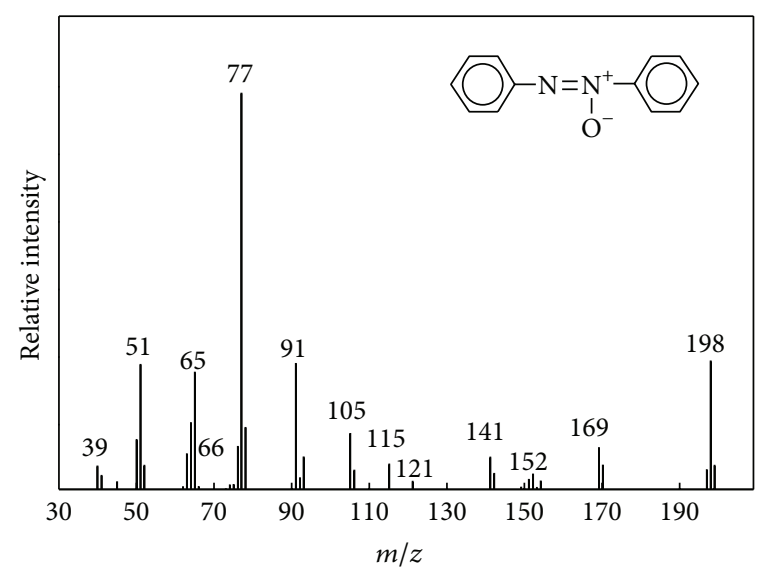

(d) Azoxybenzene

FIGURE 7: GC/MS spectra of the reductive products of NB by S-ZVI. Initial concentration of NB: $1 \mathrm{mM}$; $\mathrm{pH}$ of solution: 2.0 ; reaction time: $20 \mathrm{~min}$.

Figure 8 shows the aniline content in the product obtained from GC/MS spectra as a function of reaction time. The aniline content initially increased with reaction time but decreased after $50 \mathrm{~min}$. The reduction in the aniline content after $50 \mathrm{~min}$ was attributed to the degradation of aniline induced by $\mathrm{Fe}^{2+}$ ions produced by the oxidation of S-ZVI.

Based on the GC/MS analysis results, the mechanism for NB decomposition in the presence of S-ZVI was proposed (Figure 9). Hydrated electrons released from Reaction (4) deoxidize NB to nitrosobenzene. Further reduction of nitrosobenzene produces aniline. Azobenzene and azoxybenzene are produced as a result of the combination of reactive intermediates during the deoxidization processes. The biodegradability of aniline is known to be much higher than that of NB [5]. Therefore, NB in wastewaters can be effectively removed by combining the reduction using S-ZVI and subsequent biological processes. 


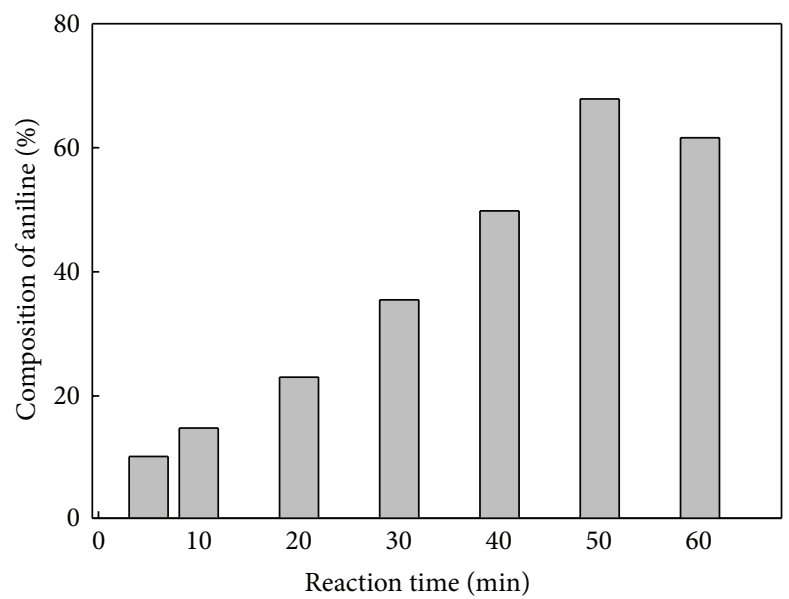

Figure 8: Content of aniline as a function of reaction time obtained at $\mathrm{pH}$ 2.0.

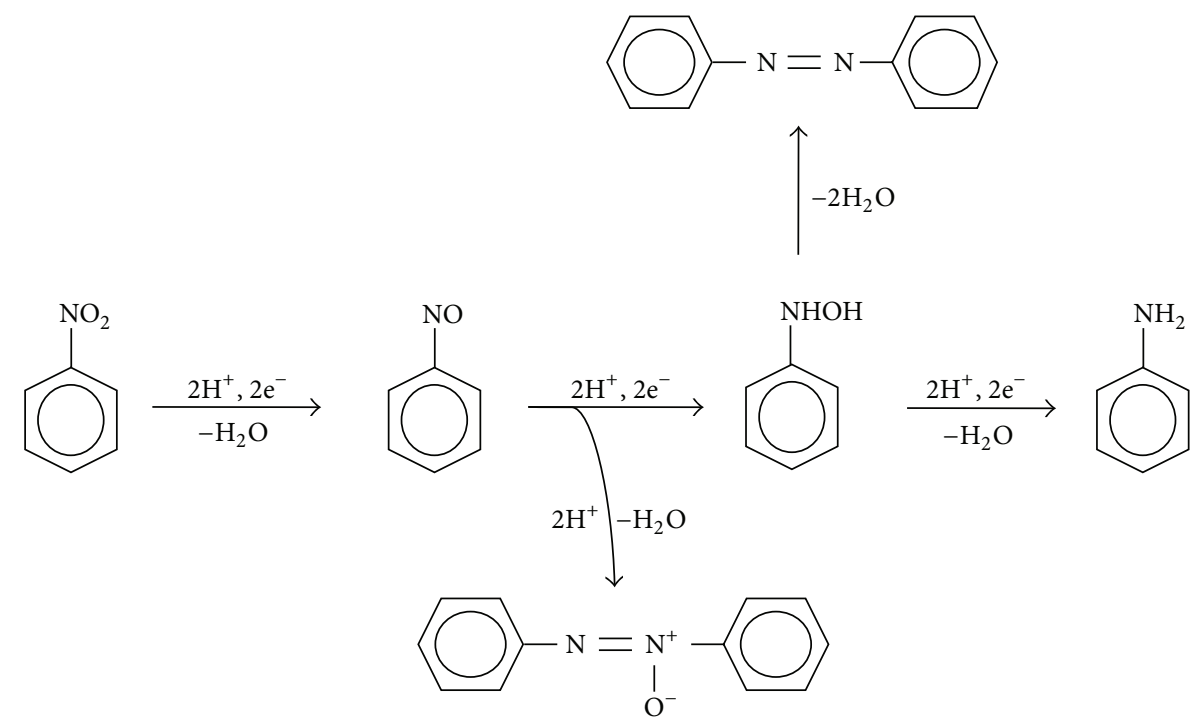

FIGURE 9: Pathways of reductive degradation of NB by S-ZVI.

\section{Conclusions}

ZVI synthesized from the iron oxide generated in a pickling line at a steel work was applied to the decomposition of NB in wastewater. The reaction activity and mechanism were evaluated experimentally. The conclusions obtained from the experiments are as follows:

(1) The particle size of the synthesized ZVI was larger than that of feedstock iron oxide particles due to sintering. The NB decomposition reaction made the S-ZVI particles smaller.

(2) HR-FETEM observation indicated the formation of passivation oxide film and the corrosion of iron in the NB solution.

(3) The NB decomposition rate increased with increasing S-ZVI dosage level and with decreasing $\mathrm{pH}$.

(4) S-ZVI was superior to C-ZVI in terms of NB decomposition activity, which was attributed to smaller particle size (larger surface area) and hence more reactive sites.

(5) The solution $\mathrm{pH}$ increased monotonously with reaction time. The aniline concentration increased with reaction time up to $50 \mathrm{~min}$ and then decreased.

(6) GC/MS analysis showed that NB is reduced to aniline via reductive products such as azobenzene and azoxybenzene.

\section{Conflict of Interests}

The authors declare that there is no conflict of interests regarding the publication of this paper.

\section{Acknowledgment}

This research was supported by Basic Science Research Program through the National Research Foundation 
of Korea (NRF) funded by the Ministry of Education (2013R1A1A2A10004797).

\section{References}

[1] O. Kuscu and D. Sponza, "Effects of nitrobenzene concentration and hydraulic retention time on the treatment of nitrobenzene in sequential anaerobic baffled reactor (ABR)/continuously stirred tank reactor (CSTR) system," Bioresource Technology, vol. 100, no. 7, pp. 2162-2170, 2009.

[2] B. E. Haigler and J. C. Spain, "Biotransformation of nitrobenzene by bacteria containing toluene degradative pathways," Applied and Environmental Microbiology, vol. 57, no. 11, pp. 3156-3162, 1991.

[3] D. S. Bhatkhande, V. G. Pangarkar, and A. A. C. M. Beenackers, "Photocatalytic degradation of nitrobenzene using titanium dioxide and concentrated solar radiation: chemical effects and scaleup," Water Research, vol. 37, no. 6, pp. 1223-1230, 2003.

[4] F. P. Van der Zee, G. Lettinga, and J. A. Field, "Azo dye decolourisation by anaerobic granular sludge," Chemosphere, vol. 44, no. 5, pp. 1169-1176, 2001.

[5] P. H. Nielsen and T. H. Christensen, "Variability of biological degradation of phenolic hydrocarbons in an aerobic aquifer determined by laboratory batch experiments," Journal of Contaminant Hydrology, vol. 17, no. 1, pp. 55-67, 1994.

[6] A. Latifoglu and M. D. Gurol, "The effect of humic acids on nitrobenzene oxidation by ozonation and $\mathrm{O}_{3} / \mathrm{UV}$ processes," Water Research, vol. 37, no. 8, pp. 1879-1889, 2003.

[7] A. Maldotti, L. Andreotti, A. Molinari, S. Tollari, A. Penoni, and S. Cenini, "Photochemical and photocatalytic reduction of nitrobenzene in the presence of cyclohexene," Journal of Photochemistry and Photobiology A: Chemistry, vol. 133, no. 12, pp. 129-133, 2000.

[8] M. Rodríguez, A. Kirchner, S. Contreras, E. Chamarro, and S. Esplugas, "Influence of $\mathrm{H}_{2} \mathrm{O}_{2}$ and $\mathrm{Fe}(\mathrm{III})$ in the photodegradation of nitrobenzene," Journal of Photochemistry and Photobiology A: Chemistry, vol. 133, no. 1-2, pp. 123-127, 2000.

[9] I. Arslan-Alaton and J. L. Ferry, " $\mathrm{H}_{4} \mathrm{SiW}_{12} \mathrm{O}_{40}$-catalyzed oxidation of nitrobenzene in supercritical water: kinetic and mechanistic aspects," Applied Catalysis B: Environmental, vol. 38, no. 4, pp. 283-293, 2002.

[10] K. Nomiya, K. Hashino, Y. Nemoto, and M. Watanabe, "Oxidation of toluene and nitrobenzene with $30 \%$ aqueous hydrogen peroxide catalyzed by vanadium (V)-substituted polyoxometalates," Journal of Molecular Catalysis A: Chemical, vol. 176, no. 1-2, pp. 79-86, 2001.

[11] W. Y. Xu, P. Li, and J. H. Fan, "Reduction of nitrobenzene by the catalyzed Fe/Cu process," Journal of Environmental Sciences, vol. 20, no. 8, pp. 915-921, 2008.

[12] A. Agrawal and P. G. Tratnyek, "Reduction of nitro aromatic compounds by zero-valent iron metal," Environmental Science and Technology, vol. 30, no. 1, pp. 153-160, 1996.

[13] Y.-S. Keum and Q. X. Li, "Reduction of nitroaromatic pesticides with zero-valent iron," Chemosphere, vol. 54, no. 3, pp. 255-263, 2004.

[14] B. H. Kim, C. Park, Y.-B. Kim et al., "Characterization of zero valent iron prepared from by-product of pickling line and its decomposition reaction activity," Korean Journal of Chemical Engineering, vol. 26, no. 6, pp. 1795-1799, 2009.

[15] H. C. Cho, D. G. Ra, S. H. Park et al., "Degradation of organic dye using zero-valent iron prepared from by-product of pickling line," Water Science and Technology, vol. 64, no. 4, pp. 960-966, 2011.

[16] Y.-I. Cho, B. H. Kim, S.-J. Kim et al., "Preparation and characterization of zero valent iron powders via transfer type reductor using iron oxide from the acid regeneration process," Advanced Powder Technology, vol. 24, no. 5, pp. 858-863, 2013.

[17] Y. Mu, H.-Q. Yu, J.-C. Zheng, S.-J. Zhang, and G.-P. Sheng, "Reductive degradation of nitrobenzene in aqueous solution by zero-valent iron," Chemosphere, vol. 54, no. 7, pp. 789-794, 2004.

[18] Y. H. Huang and T. C. Zhang, "Effects of low $\mathrm{pH}$ on nitrate reduction by iron powder," Water Research, vol. 38, no. 11, pp. 2631-2642, 2004.

[19] J. Dong, Y. Zhao, R. Zhao, and R. Zhou, "Effects of pH and particle size on kinetics of nitrobenzene reduction by zerovalent iron," Journal of Environmental Sciences, vol. 22, no. 11, pp. 1741-1747, 2010.

[20] B. K. Lavine, G. Auslander, and J. Ritter, "Polarographic studies of zero valent iron as a reductant for remediation of nitroaromatics in the environment," Microchemical Journal, vol. 70, no. 2, pp. 69-83, 2001.

[21] L. J. Matheson and P. G. Tratnyek, "Reductive dehalogenation of chlorinated methanes by iron metal," Environmental Science and Technology, vol. 28, no. 12, pp. 2045-2053, 1994.

[22] H.-M. Hung, F. H. Ling, and M. R. Hoffmann, "Kinetics and mechanism of the enhanced reductive degradation of nitrobenzene by elemental iron in the presence of ultrasound," Environmental Science and Technology, vol. 34, no. 9, pp. 1758$1763,2000$.

[23] D. Mishra and J. Farrell, "Understanding nitrate reactions with zerovalent iron using tafel analysis and electrochemical impedance spectroscopy," Environmental Science and Technology, vol. 39, no. 2, pp. 645-650, 2005. 

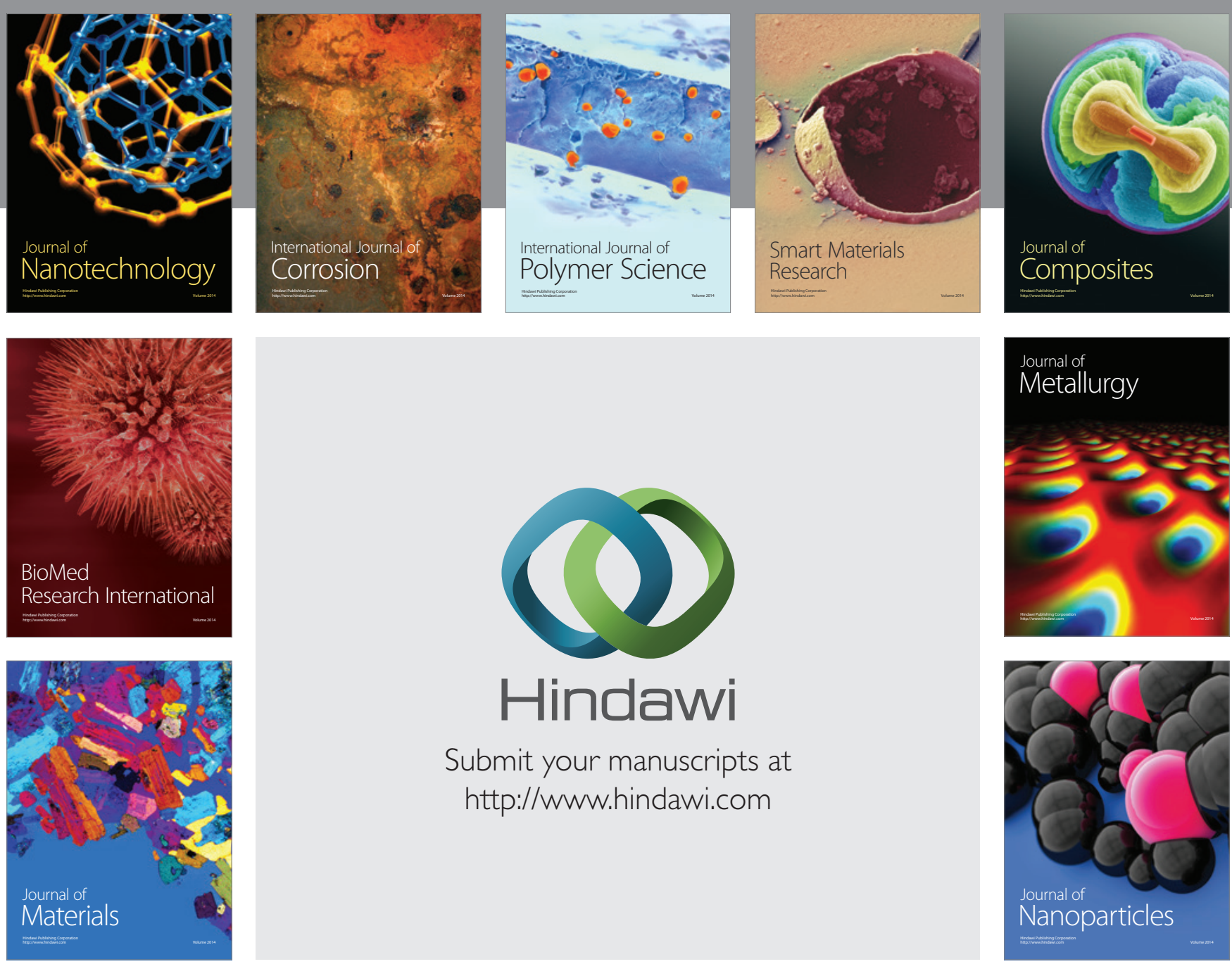

Submit your manuscripts at http://www.hindawi.com
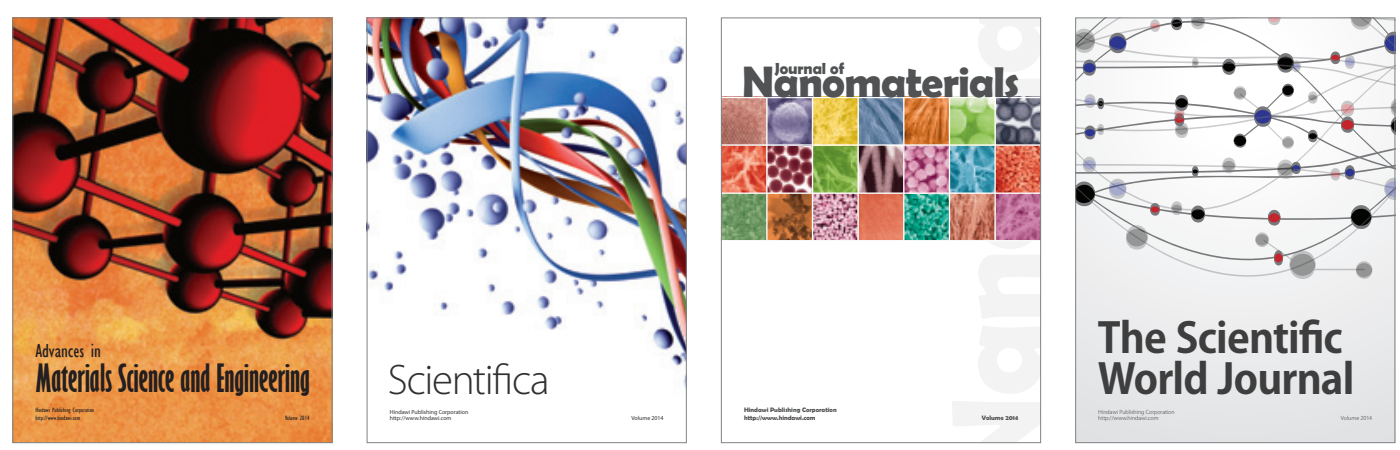

\section{The Scientific World Journal}
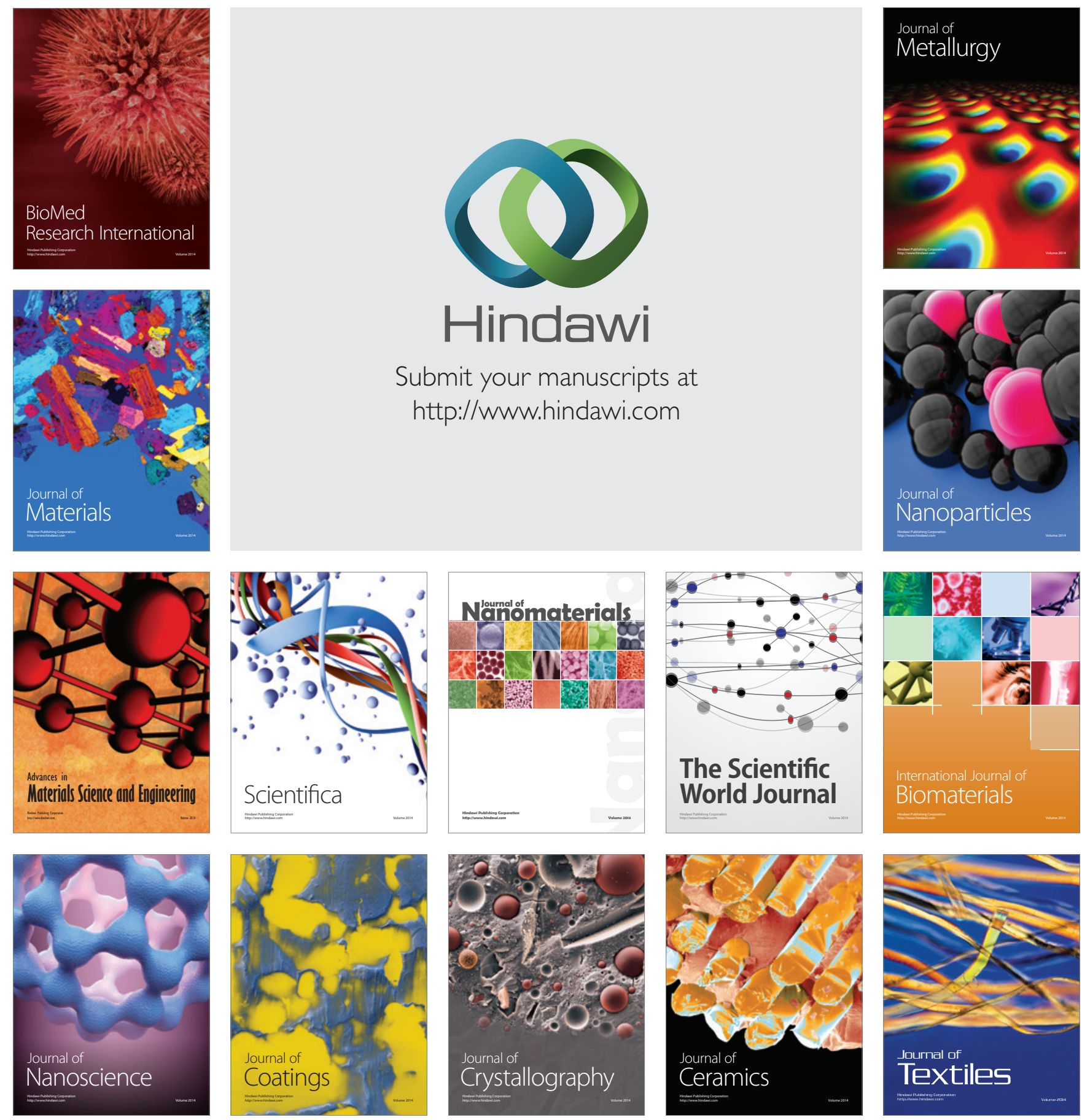